\title{
Head and Neck MRI Findings in CHARGE Syndrome
}

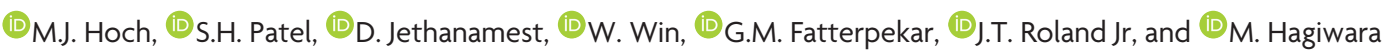

\begin{abstract}
SUMMARY: Coloboma of the eye, Heart defects, Atresia of the choanae, Retardation of growth and/or development, Genital and/or urinary abnormalities, and Ear abnormalities and deafness (CHARGE) syndrome is a disorder with multiple congenital anomalies seen on imaging. A retrospective review of 10 patients with CHARGE syndrome who underwent MR imaging of the brain as part of a preoperative evaluation for cochlear implantation was conducted. Structural abnormalities of the entire MR imaging of the head were evaluated, including the auditory system, olfactory system, face, skull base, and central nervous system. The most frequent MR imaging findings included dysplasias of the semicircular canals and hypoplasia of the frontal lobe olfactory sulci. Less frequent findings included cleft lip/palate and coloboma. Our study uncovered new findings of a J-shaped sella, dorsal angulation of the clivus, and absent/atrophic parotid glands, not previously described in patients with CHARGE. Our results emphasize the utility of MR imaging in the diagnosis and management of patients with CHARGE syndrome.
\end{abstract}

ABBREVIATIONS: CHARGE = Coloboma of the eye, Heart defects, Atresia of the choanae, Retardation of growth and/or development, Genital and/or urinary abnormalities, and Ear abnormalities and deafness; IAC = internal auditory canal; SCC = semicircular canal; SPACE = sampling perfection with application-optimized contrasts using different flip angle evolutions

C oloboma of the eye, Heart defects, Atresia of the choanae, Retardation of growth and/or development, Genital and/or urinary abnormalities, and Ear abnormalities and deafness (CHARGE) syndrome was first described in 1979 by Hall $^{1}$ in 17 children with multiple congenital anomalies, including choanal atresia, and separately by Hittner et $\mathrm{al}^{2}$ in 10 patients with coloboma. It is an autosomal dominant disorder with a North American prevalence of 1/10,000 live births. ${ }^{3,4}$ Most cases are sporadic with the $\mathrm{CHD} 7$ gene mutation identified as a cause in 2 of 3 patients. ${ }^{5,6}$ The 6 classic diagnostic criteria of the acronym described by Pagon et $\mathrm{al}^{7}$ in 1981 are ocular Coloboma, Heart defects, choanal Atresia, Retardation, Genital anomalies, and Ear anomalies. Additional anomalies have been reported, and revised criteria for the diagnosis have been proposed. Blake et $\mathrm{al}^{3}$ expanded the original criteria to include brain stem anomalies and visceral malformations. Verloes ${ }^{8}$ focused on the " $3 \mathrm{C}$ triad" of coloboma, choanal atresia, and abnormal semicircular canals and formally defined partial and atypical CHARGE syndromes.

Received October 6, 2016; accepted after revision May 13, 2017

From the Department of Radiology (M.J.H., S.H.P., W.W., G.M.F., M.H.), Section of Neuroradiology, and Department of Otolaryngology (D.J., J.T.R.), New York University Langone Medical Center, New York, New York.

Abstract previously presented at: Annual Meeting and Symposium of the American Society of Neuroradiology, April 25-30, 2015; Chicago, Illinois.

Please address correspondence to Michael J. Hoch, MD, Department of Radiology, 1364 Clifton Rd NE, Atlanta, GA 30322; e-mail: michael.hoch@emory.edu

http://dx.doi.org/10.3174/ajnr.A5297
Multiple anomalies are seen on imaging involving the ear, orbit, nasal cavity, and brain. Most neuroimaging reviews of patients with CHARGE syndrome focus on the CT findings within the temporal bone. ${ }^{9-12}$ While many temporal bone findings are clinically important for diagnosis and treatment, other findings such as cochlear nerve abnormalities are better characterized with MR imaging. However, MR imaging reviews of CHARGE syndrome are limited, focusing on only 1 or a few anomalies. ${ }^{13-15}$ To date, no single study comprehensively reports all key head and neck MR imaging findings in CHARGE syndrome, to our knowledge. The purpose of our article was to determine, by retrospective review, the head and neck structural anomalies in patients with CHARGE detected on MR imaging. Our findings will be compared with other works in the literature for concordance when available. Instructive images of the structural anomalies will be included for educational purposes.

\section{CASE SERIES}

Retrospective review of the radiology data base from 2006 to 2015 yielded 10 patients with CHARGE syndrome who underwent MR imaging of the brain as part of a preoperative evaluation for cochlear implantation. Inclusion criteria used for the clinical diagnosis of CHARGE syndrome were based on those set by Verloes. ${ }^{8}$ Typical CHARGE syndrome requires all 3 of the major criteria or 2 of the major and at least 2 minor criteria. Classification as atypical CHARGE is used for patients with 2 major and no minor or 1 


\begin{tabular}{|c|c|c|c|c|c|c|c|c|c|c|}
\hline & \multicolumn{10}{|c|}{ Subject } \\
\hline & 1 & 2 & 3 & 4 & 5 & 6 & 7 & 8 & 9 & 10 \\
\hline Sex & $M$ & $M$ & $\mathrm{~F}$ & $\mathrm{~F}$ & $M$ & $M$ & $M$ & $M$ & $\mathrm{~F}$ & $\mathrm{~F}$ \\
\hline Age at MRI (yr) & 1 & 2 & 18 & 1 & 1 & 7 & 4 & $8 \mathrm{mo}$ & 1 & 19 \\
\hline \multicolumn{11}{|l|}{ Major criteria } \\
\hline Coloboma & & + & + & & & + & & & + & + \\
\hline Choanal atresia & & & & & & + & & & + & \\
\hline SCC hypoplasia & + & + & + & + & + & + & + & + & + & + \\
\hline \multicolumn{11}{|l|}{ Minor criteria } \\
\hline Rhombencephalic dysfunction & $+^{1,2}$ & $+^{1,2}$ & $+^{1}$ & $+^{1,2}$ & $++^{1,2}$ & $+^{1}$ & $+{ }^{1}$ & $+^{2}$ & $+^{1,2}$ & \\
\hline Hypothalamohypophyseal dysfunction & $+^{3}$ & $+{ }^{4}$ & & $+{ }^{4}$ & $+^{3}$ & $++^{4}$ & & $+{ }^{4}$ & $+{ }^{4}$ & \\
\hline Malformation of ear & $++^{5,6}$ & $+^{6}$ & $+^{6}$ & $++^{5,6}$ & $+^{6}$ & $+^{6}$ & $+^{6}$ & $+^{6}$ & $+^{6}$ & $+^{6}$ \\
\hline Malformation of mediastinum & $+^{7}$ & $+^{7}$ & & $+^{7}$ & $+^{7}$ & $+^{7}$ & & $+^{7}$ & $++^{7,8}$ & $+^{7}$ \\
\hline Mental retardation & + & + & & + & + & & & + & & \\
\hline Typical CHARGE & & + & + & & & + & & & + & + \\
\hline Atypical CHARGE & + & & & + & + & & + & + & & \\
\hline
\end{tabular}

Note:- + indicates present criteria; $+{ }^{1}$, cochlear nerve hypoplastic or absent; $+^{2}$, brain stem hypoplasia; $+^{3}$, undescended testes; $+{ }^{4}$, growth delay; $+{ }^{5}$, external ear malformation; $+{ }^{6}$, inner ear malformation; $+{ }^{7}$, cardiac malformation; $+{ }^{8}$, tracheoesophageal fistula.

major and at least 3 minor criteria. The clinical diagnostic information is summarized in the Table. Five of the 10 patients were classified as having typical CHARGE syndrome. The other 5 were classified as having atypical CHARGE syndrome. None of the patients met the criteria for partial CHARGE syndrome. Three of the 5 patients with typical CHARGE had CHD7 genetic testing, and all 3 had findings positive for the mutation. Patient ages ranged from 8 months to 19 years of age (average age, 6.4 years). Seven patients were 2 years of age or younger at the time of imaging. Six patients were male. All patients were imaged on 1.5T MR imaging scanners (Aera and Avanto; Siemens, Erlangen, Germany). Nine of the 10 patients had high-resolution heavily T2-weighted 3D imaging of the temporal bones, such as CISS $(n=8)$ or T2 sampling perfection with application-optimized contrasts using different flip angle evolutions (SPACE sequence; Siemens) $(n=1)$. Five of the 10 patients had intravenous contrast administered during their MR imaging examinations.

Each bilateral structure, including the ears and orbits, was evaluated separately. The 10 cases were reviewed in consensus by 2 Certificate of Added Qualification-certified neuroradiologists with 8 and 3 years of experience, specializing in head and neck imaging. Because of the variability in MR imaging sequences, not all structures were visualized equally. This discrepancy was reflected in the final analysis. Structural abnormalities of the entire MR imaging of the head were evaluated, including the auditory system, olfactory system, face, skull base, and central nervous system.

Imaging criteria of most temporal bone findings were based on previously reported findings. ${ }^{16,17}$ Readers assessed findings of vestibular dysplasia, semicircular canal (SCC) dysplasia, cochlear dysplasia, absence of the cochlear aperture, cochlear nerve deficiency, internal auditory canal (IAC) dysplasia, and an enlarged vestibular aqueduct. ${ }^{9,14,16,17}$

The olfactory apparatus and facial structures were evaluated for abnormalities, some of which were based on other published works involving CHARGE syndrome, ${ }^{7,9,13-15}$ including olfactory bulb and sulcal hypoplasia/aplasia, choanal atresia, nasal septal integrity, cleft lip and palate, and chorioretinal coloboma. The parotid glands were included in the FOV of all examinations and were also evaluated for any abnormality.
The skull base was evaluated for abnormalities, with basioccipital hypoplasia and basilar invagination previously reported in patients with CHARGE syndrome. ${ }^{13}$ Basilar invagination was recorded if the tip of the odontoid process extended $>5 \mathrm{~mm}$ above the Chamberlain line. Other observed abnormalities of the skull base were also recorded.

Readers evaluated variations in venous drainage as previously described in patients with CHARGE. These included enlarged transmastoid emissary veins, hypoplastic sigmoid sinus or jugular foramen, aberrant petrosal sinus, venous lakes, condylar canal veins, and high-riding jugular bulbs. ${ }^{18}$

The brain was evaluated for known reported associated findings of CHARGE syndrome such as Chiari I malformation, DandyWalker spectrum, holoprosencephaly spectrum, brain stem hypoplasia, other cranial nerve dysplasia, cerebellar hypoplasia, and ventriculomegaly, ${ }^{19,20}$ and for other potential abnormalities.

MR imaging data for the 10 patients included mild variability in sequence acquisitions among patients. Therefore, the findings provided for each of the sections reflect the variability of the data. When MR imaging did not cover a pertinent area of interest, relevant data were not recorded. Fig 1 shows the percentage of structures evaluated when the finding was present.

\section{Temporal Bone}

Of the inner ears evaluated, 20 of 20 had both vestibular and SCC dysplasia (Fig 2). Because 1 patient did not have high-resolution 3D T2-weighted or CISS imaging, the following were scored of 18 total ears: Fifteen had cochlear nerve deficiency (bilateral in 7 subjects) (Fig 3), 8 had an absent cochlear aperture (bilateral in 3), and 1 had a unilateral enlarged vestibular aqueduct. One patient with bilateral cochlear nerve deficiency also had unilateral vestibular nerve deficiency. Eighteen of 18 patients also had IAC dysplasia (bilateral in 9), of which 4 were enlarged and 14 were stenotic. Sixteen of 18 patients had cochlear dysplasia (bilateral in 7) with most patients $(n=7)$ having 1.5 turns.

\section{Olfactory Apparatus and Face}

Only 2 patients of 10 had choanal atresia (Fig 4), and 1 of those 2 had a deficient posterior nasal septum. Due to FOV coverage variability, 16 olfactory structures ( 8 patients) could be evaluated; 


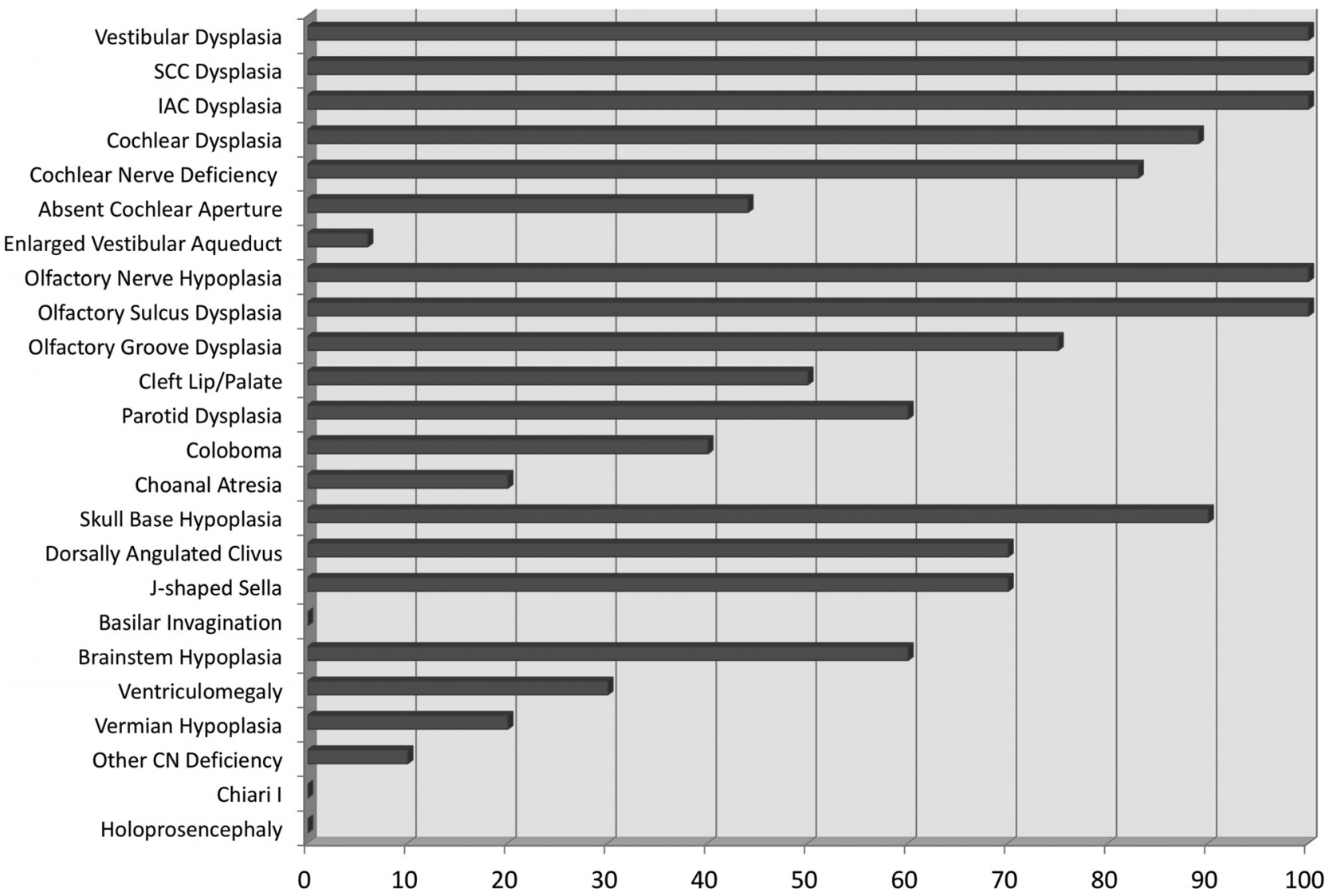

FIG 1. Bar graph of the percentage of findings present in all 10 patients with CHARGE. A percentage was chosen as the representation because some findings were bilateral and others were singular, and some of the structures could not be evaluated in all patients due to differences in imaging technique. Inner ear dysplasia, olfactory structure hypoplasia, and skull base hypoplasia were the most frequent findings.

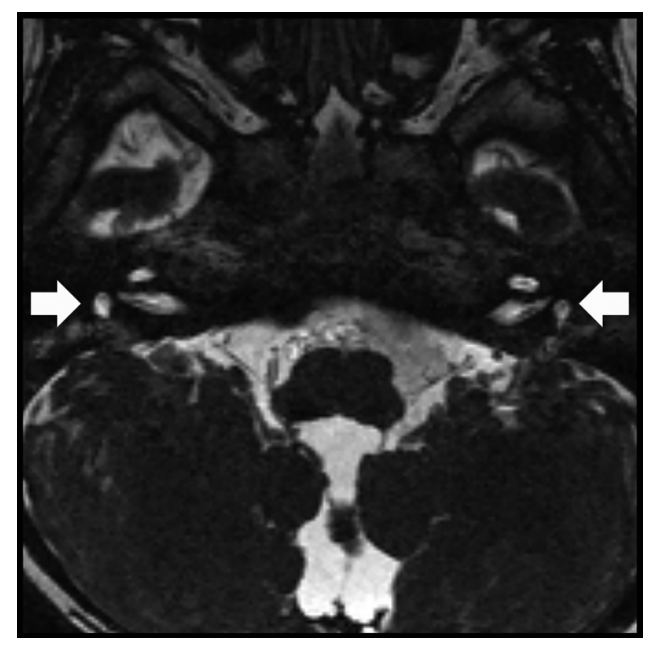

FIG 2. Axial CISS image at the level in the inner ears shows bilateral vestibular dysplasia (arrows) and absence of the semicircular canals. Inner ear malformations are among the most frequent head and neck findings in CHARGE syndrome.

however, all 16 demonstrated olfactory nerve hypoplasia with associated absent or hypoplastic olfactory sulci (Fig 5). Twelve of those 16 showed small bony olfactory grooves. Five of 10 patients had a cleft lip and cleft palate (Fig 6). Coloboma was seen in 8 of 20 imaged globes (Fig 7).

All temporal bone MRIs covered the entire parotid and parapharyngeal spaces. Two of 10 patients demonstrated aplastic bilateral parotid glands (Fig 8). Four additional patients had hypoplastic parotid glands bilaterally ( 2 of which had accessory salivary tissue along the masseter). The MR imaging scans covered the submandibular glands in 9 of 10 patients. Those 9 patients had normal-appearing submandibular glands. No ectopic salivary glands were identified in any patients.

\section{Skull Base}

Only 1 patient had a normally formed skull base. The other 9 patients had basioccipital hypoplasia, none of which had classic basilar invagination. All 10 patients had a normal relationship of the superior ossification center of the dens with respect to the anterior arch of $\mathrm{C} 1$. However, 7 of 10 demonstrated a dorsally angled clivus, with posterior displacement of an ossific density, which we interpreted to reflect an underdeveloped basioccipital ossification center and widening of the spheno-occipital synchondrosis (Fig 9). Eight of 10 had hypoplasia of the sella with 7 of those patients having a "J-shaped" appearance, with flattening and elongation of the tuberculum sella (Fig $9 B$ ). ${ }^{21}$

\section{Venous Anomalies}

In 2 of the 10 patients, the readers reported insufficient imaging data to accurately assess the venous structures. Of the remaining 8 patients, 6 demonstrated large anomalous transmastoid emissary veins (Fig 10), with 3 of these patients demonstrating this finding bilaterally. In 5 of the 6 patients with anomalous transmastoid emissary veins, the ipsilateral sigmoid sinus was hypoplastic. One 


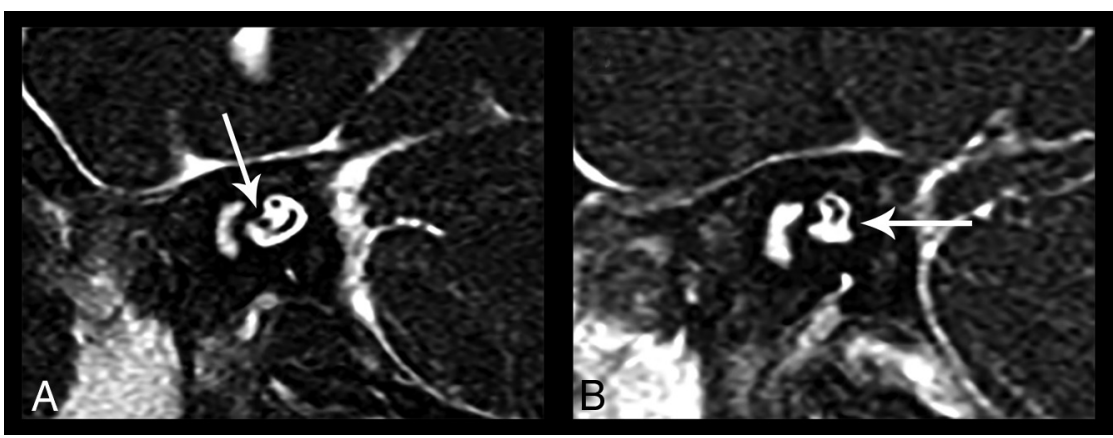

FIG 3. Oblique sagittal CISS images of the bilateral internal auditory canals show unilateral cochlear nerve deficiency. $A$, The normal right IAC has all 4 nerves. The cochlear nerve is seen in the anterior inferior quadrant of the IAC (arrow). B, The cochlear nerve is not visualized in the left IAC. There is also the suggestion of left inferior vestibular nerve hypoplasia (arrow).

\section{DISCUSSION}

This is the largest comprehensive review of the structural head and neck MR imaging findings in CHARGE syndrome. As in other reviews of CHARGE syndrome, findings reflecting the acronym were variable in frequency. Inner ear abnormalities were the most frequent finding, whereas coloboma and choanal atresia were infrequent findings. Most interesting, skull base dysplasia and olfactory complex hypoplasia, which are not part of the acronym, were 2 of the most frequent findings.

While complementary, MR imaging

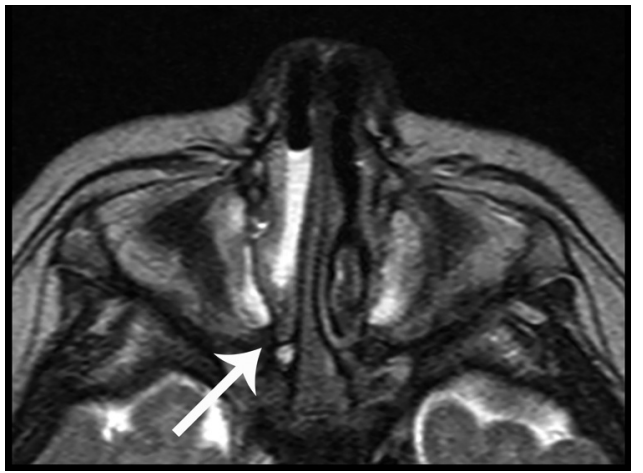

FIG 4. Axial CISS image at the level of the nasal cavity shows right choanal atresia (arrow) with retained secretions in the nasal cavity.

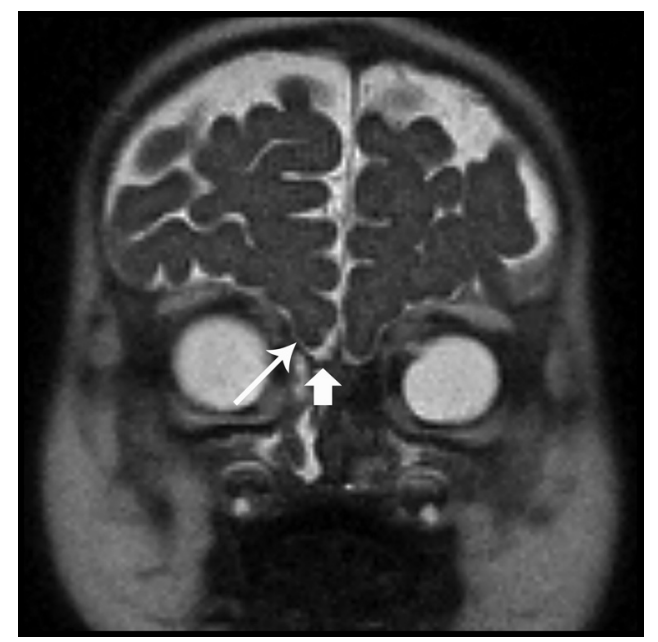

FIG 5. Coronal HASTE image shows bilateral shallow olfactory grooves with absent olfactory nerves (short arrow) and absent olfactory sulci (long arrow). The findings are labeled unilaterally.

of the patients with bilateral transmastoid emissary veins also demonstrated bilateral enlarged transoccipital emissary veins.

\section{Central Nervous System}

None of the 10 patients had findings of Chiari I malformation or holoprosencephaly. However, 5 patients showed brain stem hypoplasia, 1 had vermian hypoplasia, and 1 had both vermian and brain stem hypoplasia. Three of 10 patients had ventriculomegaly. has advantages over CT in the preoperative evaluation of pediatric deafness. ${ }^{22}$ MR imaging can identify cochlear nerve aplasia and can better delineate brain abnormalities that can potentially alter management in patients with CHARGE, who often require brain stem or cochlear implantation. While sedation is often needed for pediatric patients, MR imaging does not use radiation, which is of particular concern in the pediatric population.

There are 2 recently described and potentially major new diagnostic criteria for CHARGE syndrome. The first is olfactory complex anomalies, which include either absence or hypoplasia of the olfactory nerve, sulcus, and bony groove. This was described by Pinto et al in $2005^{23}$ and later by Blustajn et al in $2008 .{ }^{15}$ Our findings of 8 of 8 visible cases with olfactory complex anomalies are in agreement with the prior works. Pinto et $\mathrm{al}^{23}$ proposed that the olfactory abnormality and hypogonadotropic hypogonadism in patients with CHARGE syndrome overlap the main features of Kallmann syndrome. Deficiency of fibroblast growth factor signaling is thought to be responsible for olfactory bulb dysgenesis in Kallmann syndrome, ${ }^{24}$ and Pinto et al theorized that there may be potentially a functional connection between $\mathrm{CHD} 7$ and fibroblast growth factor signaling in olfactory bulb differentiation. ${ }^{15,23}$

The second newly proposed potential major criterion for CHARGE syndrome is abnormal basiocciput development. ${ }^{13} \mathrm{Ba}-$ siocciput hypoplasia results in shortening of the clivus and was previously reported to be closely associated with basilar invagination. ${ }^{25}$ The work of Fujita et al ${ }^{13}$ showed that 7 of 8 patients with CHARGE syndrome had basioccipital hypoplasia, and of those, 5 had basilar invagination. Our series demonstrated 9 of 10 patients with basioccipital hypoplasia, similar to the work of Fujita et al. However, none of our patients were judged to demonstrate basilar invagination. Instead, 7 of 10 patients demonstrated a dorsally angulated clivus with posterior displacement of an ossific density forming the inferior clivus; we interpreted this ossific density to reflect an underdeveloped basioccipital ossification center, with associated widening of the spheno-occipital synchondrosis. This finding has not been previously reported. The spheno-occipital synchondrosis is often not fused in the teenage years. We suspect that the posteriorly displaced basioccipital ossification center can mimic basilar invagination. All our patients demonstrated a normal relationship of the superior ossification center of the dens with the anterior arch of $\mathrm{C} 1$.

Our study is the first to describe a J-shaped sella associated 


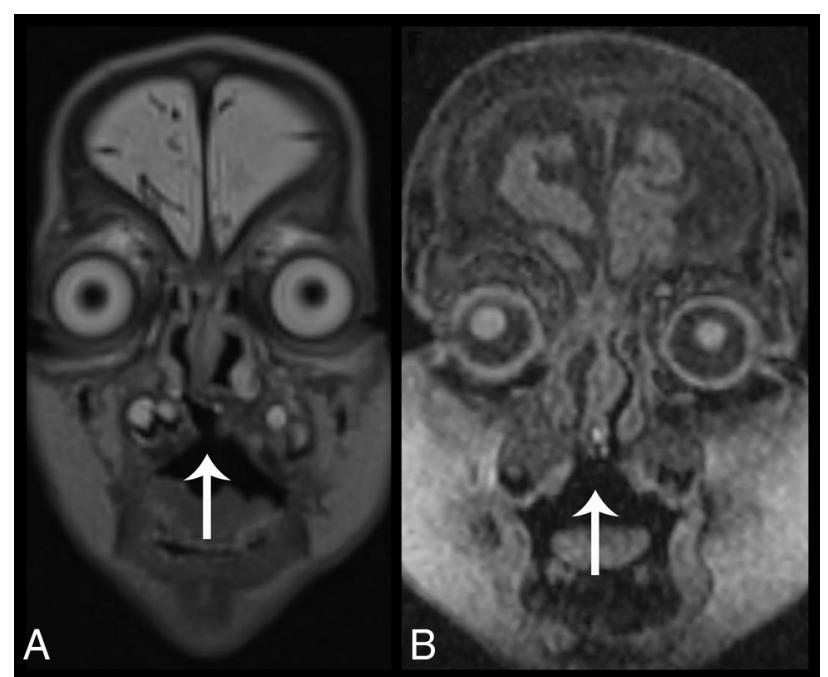

FIG 6. Cleft palate in 2 different patients. Coronal T2 SPACE reconstruction $(A)$ and 3D T1-weighted coronal image $(B)$ demonstrate a bony defect in the hard palate (arrows), allowing communication between the oral and nasal cavities.

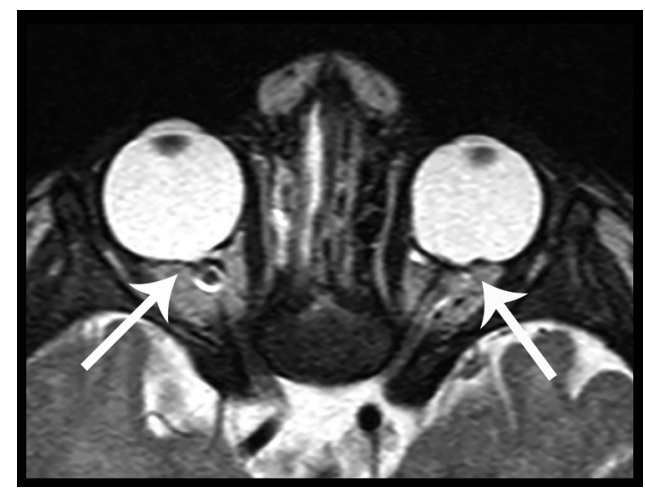

FIG 7. Axial CISS image at the level of the orbits demonstrates focal outpouching of the posterior globes at the optic disc, consistent with bilateral colobomas (arrows).

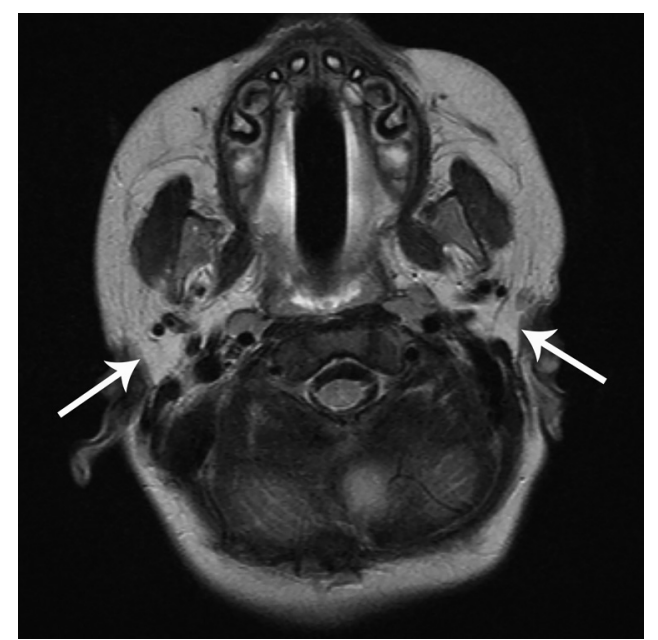

FIG 8. Axial T2-weighted image shows absent bilateral parotid glands. There is fatty tissue in both parotid spaces (arrows), with no identifiable salivary gland tissue. This finding has not been previously reported in CHARGE syndrome, to our knowledge. The normal-appearing masticator muscles argue against denervation atrophy and early fatty replacement as a cause of the parotid abnormality.

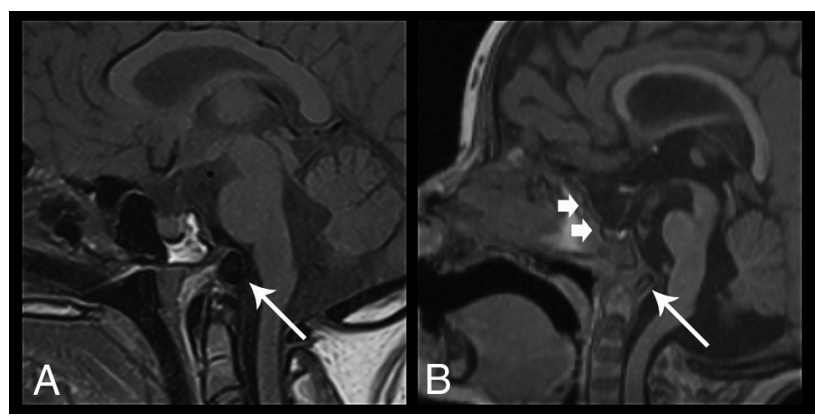

FIG 9. Sagittal images of skull base dysplasia in 2 different patients. A, Sagittal T1-weighted image demonstrates skull base hypoplasia with dorsal angulation and posterior displacement of a hypoplastic basioccipital ossification center (arrow) and widening of the spheno-occipital synchondrosis. B, Sagittal 3D T1-weighted image shows a Jshaped sella (short arrows) with flattening and elongation of the tuberculum sella. There is also evidence of a dorsally angulated clivus (long arrow), with findings similar to those in $A$. None of the patients had basilar invagination.

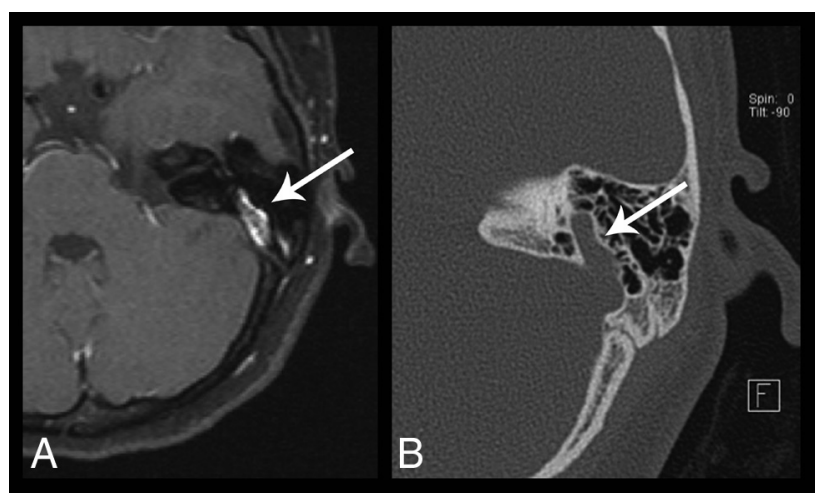

FIG 10. Axial postcontrast fat-saturated T1-weighted image $(A)$ and axial temporal bone $C T$ image $(B)$ of the left temporal bone demonstrate a prominent left transmastoid emissary vein (arrows).

with CHARGE syndrome. This appearance was described in 1923 as a skull plain film finding suggestive of intracranial extension of optic nerve glioma. ${ }^{26}$ This has been reported in patients with achondroplasia and mucopolysaccharidoses related to skull base hypoplasia, as well as in patients with intracranial aneurysms due to bony remodeling. ${ }^{21,27}$ In our patients with CHARGE syndrome, the J-shaped sella is also potentially related to the basioccipital hypoplasia.

Most surprising, 6 of 10 patients had aplastic or hypoplastic bilateral parotid glands. To our knowledge, this finding has not been previously described in association with CHARGE syndrome. Congenital absence of the salivary glands is infrequent and often involves multiple major salivary glands. ${ }^{28,29}$ In the 9 patients in whom the submandibular glands were included in the FOV, all 9 had normal-appearing submandibular glands. Furthermore, all subjects had normal-appearing masticator muscles and bilateral cranial nerve $\mathrm{V}$, which would argue against denervation atrophy and early fatty replacement as a cause of the parotid abnormalities.

The etiology of parotid gland dysplasia in patients with CHARGE is unclear. Salivary gland dysplasia can be associated with Treacher Collins syndrome and other facial anomalies, ${ }^{30}$ as well as with deafness and ear malformations. ${ }^{31}$ Parotid glands 
develop in the sixth-to-eighth week of gestation from oral ectoderm. Abnormalities of the inner ear associated with CHARGE such as vestibular and SCC dysplasias tend to occur with an insult in the sixth-to-eighth week of gestation. ${ }^{32}$ The similar timeframes of growth arrest could be explained by an insult to both developing parotid buds and primitive inner ears. Disruption of the fibroblast growth factor pathway has been reported in autosomal dominant salivary gland aplasia; as theorized with olfactory bulb dysplasia, the CHD7 mutation in a patient with CHARGE could potentially affect fibroblast growth factor signaling for parotid gland development. ${ }^{33}$

Our MR imaging findings of inner ear malformations were similar to those in prior CT reviews. When the area of interest was imaged appropriately, $100 \%$ of our patients had bilateral vestibular, SCC, and IAC dysplasia. This finding is similar to that in the studies of Lemmerling et al, ${ }^{11}$ in which all 7 patients also had these 3 abnormalities bilaterally, and Morimoto et al, ${ }^{9}$ in which all 13 patients had bilateral SCC dysplasia. ${ }^{9,11}$ In the work of Morimoto et al, only 15 of 26 ears studied had vestibular dysplasia. In the work of Admiraal et al, ${ }^{10}$ all cases had bilateral SCC absence on CT, but 2 cases had normally formed vestibules. On MR imaging, SCC abnormalities remain the most frequent temporal bone finding in patients with CHARGE.

In our study, 15 of 18 ears had cochlear nerve deficiency. This finding is similar to that in the work of Holcomb et al, ${ }^{12}$ who also showed, on MR imaging, that 13 of 14 ears in patients with CHARGE with sensorineural hearing loss also had deficient or absent cochlear nerves. There were 14 ears with stenotic IAC dysplasia, of which 3 demonstrated the presence of a normal-caliber cochlear nerve. We conclude that abnormal IAC morphology is not a reliable indicator of cochlear nerve integrity. This was similarly demonstrated by Adunka et al, ${ }^{14}$ who studied the relationship of the IAC morphology to cochlear nerve abnormalities in 14 children.

Brain stem and cerebellar hypoplasia and ventriculomegaly have been previously reported in patients with CHARGE syndrome $^{3,19}$ and were demonstrated in our patients. Six of our patients had brain stem hypoplasia, 2 patients had vermian hypoplasia without other findings of Dandy-Walker malformation, and 3 patients had ventriculomegaly. While there is a reported increased prevalence of Chiari I malformation, Dandy-Walker malformation, and holoprosencephaly in patients with CHARGE syndrome, ${ }^{34}$ none of the patients in our study demonstrated these findings.

Temporal bone venous anomalies have also been reported in patients with CHARGE syndrome, ${ }^{18}$ with large emissary veins being the most common finding. Six of our patients demonstrated large transmastoid emissary veins, with half of those present bilaterally; most of these patients showed an ipsilateral hypoplastic sigmoid sinus. Other reported anomalies, including a high-riding jugular bulb and venous lakes, were not found in our study.

This retrospective study enumerates the head and neck MR imaging findings in 10 patients with CHARGE syndrome. Because MR imaging and CT play a complementary role in surgical treatment of these patients, knowledge of the common and less frequently associated MR imaging abnormalities is necessary. Fre- quent findings such as basioccipital dysplasia and olfactory hypoplasia are not found in the CHARGE acronym; thus, further discussion into revising the diagnostic criteria of this syndrome is warranted. Novel findings reported in our study include dorsal angulation of the clivus, a J-shaped sella, and absent parotid glands.

Disclosures: J. Thomas Roland Jr—UNRELATED: Board Membership: Cochlear Americas, Advance Bionics; Comments: on advisory boards; no money paid to individual.

\section{REFERENCES}

1. Hall BD. Choanal atresia and associated multiple anomalies. J Pediatr 1979;95:395-98 CrossRef Medline

2. Hittner HM, Hirsch NJ, Kreh GM, et al. Colobomatous microphthalmia, heart disease, hearing loss, and mental retardation: a syndrome. J Pediatr Ophthalmol Strabismus 1979;16:122-28 Medline

3. Blake KD, Davenport SL, Hall BD, et al. CHARGE association: an update and review for the primary pediatrician. Clin Pediat (Phila) 1998;37:159-73 CrossRef Medline

4. Issekutz KA, Graham JM Jr, Prasad C, et al. An epidemiological analysis of CHARGE syndrome: preliminary results from a Canadian study. Am J Med Genet A 2005;133A:309-17 Medline

5. Jongmans M, Admiraal R, van der Donk KP, et al. CHARGE syndrome: the phenotypic spectrum of mutations in the $\mathrm{CHD} 7$ gene. J Med Genet 2006;43:306-14 Medline

6. Lalani SR, Safiullah AM, Fernbach SD, et al. Spectrum of CHD7 mutations in 110 individuals with CHARGE syndrome and genotypephenotype correlation. Am J Hum Genet 2006;78:303-14 CrossRef Medline

7. Pagon RA, Graham JM Jr, Zonana J, et al. Coloboma, congenital heart disease, and choanal atresia with multiple anomalies: CHARGE association. J Pediatr 1981;99:223-27 CrossRef Medline

8. Verloes A. Updated diagnostic criteria for CHARGE syndrome: a proposal. Am J Med Genet A 2005;133A:306-08 CrossRef Medline

9. Morimoto AK, Wiggins RH 3rd, Hudgins PA, et al. Absent semicircular canals in CHARGE syndrome: radiologic spectrum of findings. AJNR Am J Neuroradiol 2006;27:1663-71 Medline

10. Admiraal RJ, Joosten FB, Huygen PL. Temporal bone CT findings in the CHARGE association. Int J Pediatr Otorhinolaryngol 1998;45: 151-62 CrossRef Medline

11. Lemmerling $\mathrm{M}$, Dhooge I, Mollet $\mathrm{P}$, et al. CT of the temporal bone in the CHARGE association. Neuroradiology 1998;40:462-65 CrossRef Medline

12. Holcomb MA, Rumboldt Z, White DR. Cochlear nerve deficiency in children with CHARGE syndrome. Laryngoscope 2013;123:793-96 CrossRef Medline

13. Fujita K, Aida N, Asakura Y, et al. Abnormal basiocciput development in CHARGE syndrome. AJNR Am J Neuroradiol 2009;30: 629-34 CrossRef Medline

14. Adunka OF, Roush PA, Teagle HF, et al. Internal auditory canal morphology in children with cochlear nerve deficiency. Otol Neurotol 2006;27:793-801 CrossRef Medline

15. Blustajn J, Kirsch CF, Panigrahy A, et al. Olfactory anomalies in CHARGE syndrome: imaging findings of a potential major diagnostic criterion. AJNR Am J Neuroradiol 2008;29:1266-69 CrossRef Medline

16. Romo LV, Casselman JW, Robson CD. Temporal bone: congenital anomalies. In: Som PM, Curtin HD, eds. Head and Neck Imaging. Vol 2. 4th ed. St Louis: Mosby; 2003:1119-40

17. Swartz JD, Loevner LA. The inner ear and otodystrophies. In: Swartz JD, Loevner LA, eds. Imaging of the Temporal Bone. 4th ed. New York: Thieme; 2009:298-411

18. Friedmann DR, Amoils M, Germiller JA, et al. Venous malformations of the temporal bone are a common feature in CHARGE syndrome. Laryngoscope 2012;122:895-900 CrossRef Medline

19. Lin AE, Siebert JR, Graham JM. Central nervous system malforma- 
tions in the CHARGE association. Am J Med Genet 1990;37:304-10 CrossRef Medline

20. Byerly K, Pauli RM. Cranial nerve abnormalities in CHARGE association. Am J Med Gen 1993;45:751-57 CrossRef Medline

21. Wren MW. Significance of the so-called J-shaped sella in the diagnosis of intracranial aneurysm. Br J Ophthal 1969;53:307-09 CrossRef Medline

22. Parry DA, Booth T, Roland PS. Advantages of magnetic resonance imaging over computed tomography in preoperative evaluation of pediatric cochlear implant candidates. Otol Neurotol 2005;26: 976-82 CrossRef Medline

23. Pinto G, Abadie R, Mesnage R, et al. CHARGE syndrome includes hypogonadotropic hypogonadism and abnormal olfactory bulb development. J Clin Endocrinol Metab 2005;90:5621-26 CrossRef Medline

24. Dodé C, Hardelin JP. Kallmann syndrome: fibroblast growth factor signaling insufficiency? J Mol Med (Berl) 2004;82:725-34 CrossRef Medline

25. Smoker WR. Craniovertebral junction: normal anatomy, craniometry, and congenital anomalies. Radiographics 1994;14:255-77 CrossRef Medline

26. Martin P, Cushing H. Primary gliomas of the chiasm and optic nerves in their intracranial portion. Arch Ophthal (NY) 1923; 52:209-41

27. Zafeiriou DI, Batzios SP. Brain and spinal MR imaging findings in mucopolysaccharidoses: a review. AJNR Am J Neuroradiol 2013;34: 5-13 CrossRef Medline

28. McDonald FG, Mantas J, McEwen CG, et al. Salivary gland aplasia: an ectodermal disorder? J Oral Pathol 1986;15:115-17 CrossRef Medline

29. Higashino H, Horii T, Ohkusa $\mathrm{Y}$, et al. Congenital absence of lacrimal puncta and of all major salivary glands: case report and literature review. Clin Pediatr (Phila) 1987;26:366-68 CrossRef Medline

30. Cohen M. Mandibulofacial dysostosis. In: Bergsma D, ed. Birth Defect. Baltimore: Williams and Wilkins; 1974:465-74

31. Hollister DW, Klein SH, De Jager HJ, et al. The lacrimo-auriculodento-digital syndrome. J Pediatr 1973;83:438-44 CrossRef Medline

32. Joshi VM, Navlekar SK, Kishore GR, et al. CT and MR imaging of the inner ear and brain in children with congenital sensorineural hearing loss. Radiographics 2012;32:683-98 CrossRef Medline

33. Nie X, Luukko K, Kettunen P. FGF signalling in craniofacial development and developmental disorders. Oral Dis 2006;12:102-11 CrossRef Medline

34. VanGilder JC, Menezes AH, Dolan KD. The Craniovertebral Junction and Its Abnormalities. Mount Kisco: Furuta; 1987:113-18 